Madrygal. Revista de Estudios Gallegos

ISSN: 1138-9664

\title{
Nacionalismo, saudade, mito e historia en Fernando Pessoa y Luís Seoane
}

\author{
Antía Fernández Martínez
}

Recibido: 3 de abril de 2017 / Aceptado: 20 de setembro de 2017

Resumen. En dos vidas literarias tan aparentemente distantes entre sí como pueden ser las de Fernando Pessoa (Lisboa, 1888-1935) y Luís Seoane (Buenos Aires, 1910 - A Coruña, 1979) confluyen, sin embargo, la visión crítica sobre la historia nacional (tanto portuguesa como gallega) y el proceso de desmitificación de la saudade. El propósito del presente artículo es el análisis de cómo estos elementos (historia, mito, saudade) se relacionan entre sí en la obra de ambos poetas, y a su vez, dialogan con los nacionalismos de su tiempo y con la historia de sus países.

Palabras clave: Nacionalismo; saudade; mito; historia; saudosismo; piñeirismo; Pessoa; Seoane.

\section{[gl] Nacionalismo, saudade, mito e historia en Fernando Pessoa e Luís Seoane}

Resumo. En dúas vidas literarias tan aparentemente distantes entre si como poden ser as de Fernando Pessoa (Lisboa, 1888-1935) e Luís Seoane (Bos Aires, 1910 - A Coruña, 1979), conflúen, no entanto, a visión crítica sobre a historia nacional (tanto portuguesa como galega) e o proceso de desmitificación da saudade. O propósito do presente artigo é a análise de como estes elementos (historia, mito, saudade) se relacionan entre si na obra de ambos os dous autores e, á súa vez, dialogan cos nacionalismos do seu tempo e coa historia dos seus países.

Palabras chave: Nacionalismo; saudade; mito; historia; saudosismo; piñeirismo; Pessoa; Seoane.

\section{[en] Nationalism, Saudade, Myth and History in Fernando Pessoa and Luís Seoane}

\begin{abstract}
The literary works of Fernando Pessoa (Lisbon, 1888-1935) and Luís Seoane (Buenos Aires, 1910 - A Coruña, 1979) are, apparently, very distant from each other. Nevertheless, they do coincide in two key issues among others: the critical vision of the national (Portuguese and Galician) history and the demythologization process of saudade. The main aim of this paper is to analyze how these elements (history, myth, saudade) relate to each other and how do they establish a conversation with their contemporary nationalisms and the history of their countries.
\end{abstract}

Keywords: Nationalism; Saudade; Myth; History, Saudosism; Piñeirism; Pessoa; Seoane.

Sumario. 1. Introducción. 2. Fernando Pessoa. 3. Luís Seoane. 4. Conclusiones y actualidad del tema. 5. Referencias bibliográficas.

Como citar: Fernández Martínez, A. (2017): "Nacionalismo, saudade, mito e historia en Fernando Pessoa y Luís Seoane", Madrygal. Revista de Estudios Gallegos 20, pp. 41-52.

\footnotetext{
Universidad Complutense de Madrid, Departamento de Filología Románica, Filología Eslava y Lingüística General.

E-mail: antiafermar@gmail.com
} 


\section{Introducción}

El siglo XX ha quedado grabado en los anales de la memoria contemporánea como el sangriento resultado de los nacionalismos exacerbados, de los caudillos y "héroes de la patria" enloquecidos por el sueño de la gloria. El siglo de las guerras y las revoluciones, pero también el de los artistas fascinados por los nuevos descubrimientos, por la nueva ciencia, por el horror de la guerra, alumbrando una nueva forma de arte nunca anteriormente vista.

Todo ello no pasó de largo por la también azotada Península Ibérica, dejando su impronta en la obra poética de Fernando Pessoa (Lisboa, 1888-1935) y de Luís Seoane (Buenos Aires, 1910 - A Coruña, 1979), trabajos poéticos en los que la cuestión nacional (muy ligada al concepto de saudade) y el debate identitario se funden con la historia y con el mito.

Así, el presente artículo propone ofrecer un breve análisis comparativo de estos aspectos (nacionalismo, saudade, mito, historia, literatura) en la obra de ambos autores, teniendo en cuenta la distancia temporal e histórica que media entre ellos, así como la tan diferenciada línea poética que siguen, mucho más filosófica en el caso de Pessoa y claramente política y social en el de Seoane.

Dada la gran polisemia de la palabra saudade $^{2}$, la gran cantidad de significados que su sola mención evoca, hemos de aclarar en primer lugar la definición que hemos tomado para guiar el trabajo. Así, entendemos la saudade en su sentido más amplio, como el sentimiento ${ }^{3}$ causado por una ausencia (sea esta de la naturaleza que sea: ausencia de un amor, de la tierra natal, de un ideal...) en su dimensión temporal; es decir, podemos definir la saudade como el sentimiento provocado por el recuerdo de una ausencia que se evoca en el presente y que se proyecta en el futuro a través de un deseo. Por ejemplo, la saudade de la tierra se manifiesta en el deseo futuro del emigrante de volver a ver el hogar antes de morir.

Así mismo, es importante señalar que la plasmación del pensamiento nacionalista de Pessoa y de Seoane en su obra poética bebe directamente de la relación que estos poetas tuvieron con las corrientes nacionalistas de su tiempo: el saudosismo en el caso del portugués y el piñeirismo en el del gallego.

El saudosismo es el nombre por el que se conoce a la corriente cultural de la que será Teixeira de Pascoaes (Amarante, 1877 - Gatão, 1952) su principal teorizador. Según propugnaban los saudosistas, la saudade era "a suprema criação sentimental da Raça" portuguesa ${ }^{4}$ (Pascoaes 1988: 32). Pascoaes consideraba que el sentimiento saudoso era el espíritu mismo del pueblo portugués, la personificación de su ethos, y que la situación de "decandencia" en la que se encontraba sumida la "raza" portuguesa tan sólo podría paliarse a través de la recuperación de la saudade como expresión originaria de esa alma portuguesa, ya que entendía que el desarrollo de la "raza" portuguesa había ido paralelo al perfeccionamiento del sentir saudoso. La saudade era el nuevo rey Sebastián ${ }^{5}$ que esperaba el pueblo portugués.

Por otra parte, se conoce como piñeirismo a la corriente ideológica nacida del pensamiento de Ramón Piñeiro (Láncara, 1915 - Santiago de Compostela, 1990), intelectual y galleguista que intentó crear un sistema filosófico y ontológico propio del noroeste peninsular a partir del sentimiento saudoso, entendido este,

2 No podemos evitar referirnos a la importante tradición y significación literaria que la palabra posee, llegando a codificarla literariamente, así como la gran utilización política que sobre ella ha operado el nacionalismo, aspectos cruciales a tener en cuenta a la hora de acercarnos al presente trabajo, en el que hemos tenido que eludir cuestiones recurrentes en el análisis del vocablo tales como su equivalencia lingüística, su etimología, su relación con términos afines como soledad o morriña, etc. dada la limitación de espacio del estudio.

3 Sentimiento que no ha de ser necesariamente negativo, aunque, especialmente por la asimilación, la lectura sesgada y/o la utilización política de figuras como Rosalía de Castro o António Nobre se asocia popularmente a un estado melancólico o de tristeza profunda. La obra poética de autores como Seoane muestra cómo el tema literario de la saudade puede ser abordado desde otras perspectivas.

4 Entendida y usada la palabra raza en el sentido dado por los nacionalistas de comienzos de siglo como Teixeira de Pascoaes.

5 El rey portugués Sebastián I, “o Desejado” (1554-1578) es figura clave en el imaginario nacionalista luso, de quien toma el nombre el sebastianismo, movimiento que simbolizó en la vuelta del desaparecido monarca (muerto el 4 de agosto de 1578 en la batalla de Alcazarquivir sin dejar heredero) la restauración de la perdida grandeza portuguesa. 
ontológicamente, como la experiencia humana que mejor recogería el peculiar matiz de sentimentalismo que caracterizaría a Galicia y Portugal (Piñeiro 2001: 28). Piñeiro, con su filosofía de la saudade, buscaba dotar al pueblo luso-galaico de una forma propia de pensamiento que impulsase su avance cultural y espiritual: "Só así, tendo conciencia da nosa personalidade verdadeira, poderemos seguir sendo un pobo. De non termos esa conciencia, quedaremos reducidos á simple condición de país habitado" (Piñeiro 2001: 94), coincidiendo en este punto el proyecto de Piñeiro con el que había planteado no hacía más de medio siglo antes Teixeira de Pascoaes en Portugal: la utilización del sentimentalismo y de la saudade como factores diferenciadores e identitarios.

\section{Fernando Pessoa}

Para analizar en la obra de Fernando Pessoa los aspectos anteriormente enumerados tomaremos su poemario Mensagem (1934), en el que desarrolla literariamente las ideas nacionalistas y sebastianistas que desarrolló de forma teórica en diversos artículos compilados en el volumen Portugal, sebastianismo e Quinto Império (1986), así como los poemas de Álvaro de Campos (1990) titulados "Lisbon Revisited": "Lisbon Revisited (1923)" y "Lisbon Revisited (1926)".

El nacionalismo de Pessoa ha de ser estudiado a la luz del saudosismo y de la relación, ambigua y contradictoria, que mantuvo con la figura de Teixeira de Pascoaes. Y aunque son muchos los aspectos al respecto que podríamos tomar en consideración, nos centraremos en aquellos que tienen una plasmación directa en Mensagem (1996): Pessoa creía en la llegada de un Quinto Imperio universal, el portugués, que coincidiría con la venida del legendario y mesiánico rey Sebastián, simbolizando así su regreso la recuperación por parte de Portugal de aquello que había perdido con su desaparición, como su independencia y su carácter imperial (Pessoa 1986: 151).

Pessoa concibe al rey Sebastián como un mito, ya que creía en la fuerza generadora que este tipo de relatos tenían en las naciones: "Há só uma espécie de propaganda com que se pode levantar a moral de uma nação (...) um grande mito nacional" (Ibid. 165). Para Pessoa, en Portugal este mito estaba ya configurado en la figura del rey Sebastián, por lo que la creación de la leyenda no era necesaria; sólo hacía falta renovarla. Así, Pessoa concibe el sebastianismo como un ismo literario o artístico, esto es, un movimiento vanguardista más "entre o conjunto de planos de revoluções culturais fundadas em apreciações estéticas da realidade" (Uribe y Sepúlveda 2012: 144), y al rey Sebastián como un personaje que entra a formar parte del mundo poético y literario del autor, ya sea para usarlo como referencia histórica o como leitmotiv mesiánico (Ibid. 145), tal como ocurre en Mensagem:

\section{Grécia, Roma, Cristandade, \\ Europa - os quatro se vão \\ Para onde vai toda a idade. \\ Quem vem viver a verdade \\ Que morreu D. Sebastião? \\ (“Segundo. O Quinto Império", vv. 25-30)}

Para Pessoa la relación entre sebastianismo y saudosismo se basaba en la concepción del segundo como "a base intelectual e moral ao sebastianismo, puramente popular" (Pessoa 1986: 112), es decir, el saudosismo entendido como el sebastianismo en su desarrollo teórico; y aunque la concordancia ideológica entre Pessoa y Teixeira de Pascoaes no siempre se produjo $^{6}$, sí coincidían en ciertos aspectos: ambos creían en lo perjudicial de los elementos extranjeros en Portugal, por lo que era necesario que el país tomara consciencia de sí mismo para que en el sentimiento patriótico solo tuvieran lugar aquellos componentes puramente portugueses, a través de los cuales se conseguiría la universalidad del imperio futuro (Ibid. 110-111) y en el poder del arte y de la literatura, de la cultura, como verdadero motor de la regeneración nacional: "a decadencia artística e literária é o fenómeno mais representativo da decadencia esencial duma nação" (Ibid. 133). Ambos, además, no se limitaron únicamente a señalar el hecho de una forma pasiva, sino que intentaron contribuir activamente a revertir

6 Divergencias en las que, por la limitación del presente artículo, no podemos detenernos en su análisis, aunque sí podemos señalar como puntos destacados en esta confrontación ideológica las divergencias en la concepción del venidero Quinto Imperio o del progreso. 
esta situación a través de la creación literaria y poética. Pessoa era consciente de que el imperio futuro portugués no podría ser ni una gran potencia a nivel económico ni a nivel militar, pero sí podía serlo culturalmente (Ibid. 163).

Pero Pessoa, pese a creer en las ideas nacionalistas desarrolladas por los saudosistas, tenía una visión mucho más cosmopolita, especialmente en el plano intelectual, y estaba mucho más abierto a las nuevas corrientes literarias que estaban llegando de Europa, desarrollando una tercera vía artística en la que los temas tradicionales portugueses se integraban en una estética modernista (Sadlier 1968: 32), lo que no le impidió imitar en algunas ocasiones formas literarias populares entre los saudosistas, como el estilo de Garret (Ibid. 35). Pessoa apoyaba las tesis fundamentales del saudosismo, pero como movimiento artístico le resultaba limitado, ya que creía que era posible un imperio, e incluso un arte, al mismo tiempo portugués y universal (Pessoa 1986: 159). La idea pessoana de "quebrar com a ideia de Pátria como entidade oposta a qualquer outra coisa neste mundo" (Ibid. 110) entraba en conflicto con las tesis saudosistas. El nacionalismo de Pessoa fue un nacionalismo místico, "poético" (Lourenço 1996: 16) que se oponía al nacionalismo político defendido por otros intelectuales y que Pessoa no apoyaba (Uribe y Sepúlveda 2012: 158), ya que lo que realmente le interesaba a Pessoa era el "conteúdo místico presente na noção de nacionalidade portuguesa" (Ibid. 142).

Es por ello que conceptos recurrentes en los discursos sebastianistas, adaptados al sentir poético y metafísico del poeta, como patria o destino (tanto nacional como personal) adquieren una gran relevancia en Mensagem y en la obra de Pessoa. Al respecto de este último, el lisboeta creía en lo profético de la venida del Quinto Imperio, personificada especialmente en la figura del zapatero Bandarra, a quien también dedica un poema en Mensagem. Así, varias profecías a lo largo del tiempo habrían anunciado la venida de este Quinto Imperio universal y portugués, por lo que el sino de Portugal como nación ya habría estado escrito. Es por ello que en Mensagem se repite en varias ocasiones la idea de que la conquista portuguesa ha sido un mandato divino y no de los hombres, que fue Dios quien izó realmente las velas de sus barcos y el destino quien lanzó al portugués al mar:
Outros poderão achar

$\mathrm{O}$ que, no nosso encontrar,

Foi achado, ou não achado,

Segundo o destino dado.

("VI. Os colombos", vv. 3-6)

De esta manera, como también ocurre en otras obras cumbres de la literatura portuguesa, como en las de Camões o en António Nobre, el hado de Portugal y el hado del poeta se funden en uno solo. En el caso de Mensagem, Pessoa se identifica, "se esconde y se muestra" a sí mismo bajo la figura de don Fernando (Lourenço 1996: 21), con esa capacidad tan pessoana de desdoblarse en diferentes personalidades. De igual manera que D. Fernando habría sido elegido por Dios para luchar en batalla por la conquista de la gloria portuguesa, Fernando Pessoa habría sido señalado para, ya no con la espada sino con la poesía, hacer resurgir el olvidado esplendor luso. De esta manera, el mensaje divino del poema "Don Fernando. Infante de Portugal" está dirigido tanto a D. Fernando como a su homónimo Fernando Pessoa, quien ya también en su obra teórica se había identificado con el rey Sebastián:

Sagrou-me seu em honra e em desgraça,

(...)

Pôs-me as mãos sobre os ombros e doirou-me

A fronte com o olhar;

E esta febre de Além, que me consome,

E este querer grandeza são seu nome

Dentro em mim a vibrar.

E eu vou, e a luz do gladio erguido dá Em minha face calma.

(vv. 3-12)

En Mensagem la historia nacional del pueblo portugués es ilustrada por héroes de dominio popular en la cultura portuguesa (Lourenço 1996: 9), una serie de héroes-mitos basados en personajes históricos que "prefiguraron al único Héroe futuro, restaurador de nuestro imperio perdido en los arenales de África, en Alcarzaquivir" (Ibid. 18). Estos héroes-mito serían los mejores representantes de su época, simbolizando así en cada uno de ellos fuerzas inmateriales que los transcenderían como seres individuales, inscribiendo al sebastianismo en el relato de la historia universal. Así convierte Pessoa lo particular y genuinamente portugués del sebastianismo en universal (Uribe y Sepúlveda 2012: 147-148), ya que esos "Homens de Genio" -entre los que Pessoa se incluía a sí mismo- representarían a los individuos a los 
que corresponde y ha correspondido la creación del sentido místico de la nacionalidad (Ibid. 159).

Ya anteriormente a Pessoa, Camões había sido concebido como un héroe-mito al haber sabido condensar el alma portuguesa en la épica de Os Lusíadas. Al publicarse Mensagem, este fue leído por algunos "como un segundo Os Lusíadas" (Lourenço 1996: 14) y, de hecho, Pessoa no sólo nunca negó su ambición de suplantar a Camões como gran poeta luso-universal y su visión épica de la historia portuguesa por una más profunda y universal (Lourenço 1996: 15), sino que incluso se consideraba a sí mismo un "super-Camões", el primer poeta portugués universal sin dejar de ser por ello profundamente nacional (Uribe y Sepúlveda 2012: 143), el “intérprete do Quinto Império, especie de Dom Sebastião do imperio universal da cultura lusíada que ele mesmo anunciou" (Lupi 1987: 463), configurándose como el nuevo hacedor de mitos de la cultura portuguesa (Uribe y Sepúlveda 2012: 157): “O próprio Camões não foi mais que o que esqueceu fazer. (...) O Infante, Albuquerque e os outros semideuses na nossa glória esperam ainda o seu cantor" (Pessoa 1986: 160).

Para conectar este pensamiento nacionalista con las formas de saudade que aparecen en la poesía del lisboeta hemos de profundizar en la metafísica que Pessoa desarrolla en sus versos. Para Pessoa el alma por su naturaleza divina es inmortal (Pessoa 1986: 150), estando, por lo tanto, fuera del tiempo (Lourenço 1999: 156), de lo que se deduce que el alma, el yo, puede tener saudade de una vida pasada, no conocida conscientemente pero sentida y anhelada:

De vez en quando luze em minha mágoa, (...)

E eu relembro de tempos mais antigos

Que a minha consciencia da ilusão

Águas divinas percorrendo o chão

De verdores uníssonos e amigos,

E a ideia de uma Pátria anterior

À forma consciente do meu ser

("Meu pensamento é um rio subterrâneo", vv. 9-18)

Esta vida pasada es concebida en el poemario como una patria anterior, entremezclándose saudade, nacionalismo y poesía, ya que Mensagem no es sino la plasmación poética de la saudade de la patria que siente el poeta, de una "patria desde siempre perdida" (Lourenço 1996: 20); esa patria que es tanto Portugal como uno mismo y que se proyecta más en el futuro que en el pasado. Aunque el pueblo portugués ha sido despojado de todo el esplendor del imperio perdido, sigue guardando para sí el mar y la saudade, su verdadera patria y elementos clave en la configuración del ethos e historia portuguesa, confundiéndose y mezclándose destino y patria personal y nacional:

Restam-nos hoje, no silêncio hostil,

O mar universal e a saudade.

("XII. Prece", vv. 3-4)

En esta saudade de sí mismo, de esa patria interior, también entra en juego otro elemento fundamental de la poesía pessoniana: el tiempo, ya que lo que hace Pessoa en Mensagem es sustraer la realidad y la historia a la esfera del mito, anulando, por lo tanto, su condición temporal (Lourenço 1996: 20), pero al mismo tiempo poniéndola de relieve al entender la historia de Portugal como un proceso evolutivo que ha de culminar en el Quinto Imperio. Es decir, como mito, la historia portuguesa es atemporal, pero al partir este de un hecho histórico (la conquista marítima portuguesa) convertido en devenir literario por la pluma del poeta, puede "hablarse entonces de realidad mitológica sin incurrir en contradicciones" (Pérez López 2011: 21):

O mito é o nada que é tudo.

(...)

Assim a lenda se escorre

A entrar na realidade,

E a fecundá-la decorre.

Em baixo, a vida, metade

De nada, morre.

("Primeiro: Ulisses", vv. 1-15)

Esta contradicción en el concepto de tiempo también se plasma en la concepción saudosa. Para Pessoa la saudade de sí mismo que produce esta existencia anterior tiene su expresión en la banal temporalidad que envuelve al ser humano y de la que no puede escapar. Así, este conflicto -conflicto con la "pura insconsistência do devir" que significa el tiempo-se acaba traduciendo en una "vertiginosa busca do ser" (Lourenço 1999: 159). Es decir, la saudade expresada por Pessoa en los poemas a analizar es la consecuencia de la consciencia de la temporalidad del ser humano, la consciencia de ser un ser en el tiempo. 
Del conflicto entre el hombre y el tiempo, de la temporalidad vivida como angustia o como tedio absoluto, será, de todos los heterónimos del lisboeta, Álvaro de Campos su máximo exponente (Ibid. 162), por lo que la analizaremos en sus dos poemas "Lisbon Revisited (1923)" y "Lisbon Revisited (1926)", en cuyos versos se mezcla la saudade ontológica con la saudade de la infancia, ya que es esta última forma de saudade la que hace consciente al yo poético del paso del tiempo y de cómo este ha obrado sobre el individuo. Al recordar su infancia, el yo lírico es consciente de que nunca podrá volver a ella y de que el paso del tiempo, por tanto, escapa a su control: "nas qualidades da infancia -alegría, inocência, jogo, simplicidade- converge uma saudade que transcende a histórica, uma saudade de algo que não é nem foi" (Lupi 1987: 466).

En "Lisbon Revisited (1923)" el poeta compara la Lisboa de su presente con la que recuerda de su niñez, para llegar a la conclusión de que todo sigue igual, pero no igual en su apariencia física, sino en su verdad ontológica y en su vacío de significado:

Ó céu azul -o mesmo da minha infancia-,

Eterna verdade vazia e perfeita!

Ó macio Tejo ancestral e mudo,

Pequena verdade onde o ceu se reflecte!

Ó magoa revisitada, Lisboa de outr'ora de hoje!

Nada me daes, nada me tiraes, nada sois que eu [me sinta.

(vv. 28-33)

Así, en la poesía metafísica pessoana, la saudade cumple un papel fundamental: "pasando para além das contingências, se tornar um estado não apenas psíquico, mas existencial, de comunhão total com o tempo e o mundo, e com isso imobilizar o presente, e apreender a realidade numa intuição fundamental" (Lupi 1987: 466); es decir, la diferencia irreconciliable entre realidad y subjetividad, el corte radical entre el yo y el mundo, intenta salvarlo Pessoa a través de la saudade metafísica. Así, al contemplar la urbe y conversar con ella, el sujeto se hace consciente de las varias ciudades que se solapan en su revisitación: la ciudad pérdida de su infancia, la ciudad del turbulento presente, y una ciudad que es, al mismo tiempo, ninguna de las dos. La saudade hace converger la ciudad de su niñez con la de su presente, solapándolas, y creando una ciudad imposible, irreal, un espacio multitemporal en el que el yo irremediablemente se pierde (Ibid.):

Outra vez te revejo,

Cidade da minha infancia pavorosamente perdida...

Cidade triste e alegre, outra vez sonho aqui...

$\mathrm{Eu}$ ? Mas sou eu o mesmo que aqui vivi, e aqui [voltei,

E aqui torne a voltar, e a voltar,

E aqui de novo tornei a voltar?

Ou somos, todos os Eu que estive aqui ou estiveram.

Uma série de contas-entes ligadas por um

[fio-memoria,

Um série de sonhos de mim de alguem de fóra de $[\mathrm{mim}$ ?

(“Lisbon Revisited (1926)”, vv. 31-39)

Nos encontramos por lo tanto, aquí, con una diferencia fundamental entre la saudade que Álvaro de Campos nos muestra en sus poemas y el papel dado a la saudade por los saudosistas, ya que mientras para los segundos este sentimiento era un sentimiento positivo, regenerador, que serviría para recuperar la gloria cultural pérdida, en Pessoa/Álvaro de Campos se convierte en un sentimiento con una importante carga negativa, en la consciencia de la soledad del individuo, de la pérdida; en angustia existencial (Ferraz de Paula 2009: 57).

\section{Luís Seoane}

Contradictoria y ambigua fue también la relación del pintor, poeta y periodista Luís Seoane (1910-1979) con el piñeirismo. Nos trasladamos ahora al otro lado del Miño para analizar la dialéctica que se produjo en los años 50 entre los intelectuales gallegos afincandos tanto en Galicia como en América con el piñeirismo, para analizar cómo las ideas políticas de Seoane fueron plasmadas en su poemario Fardel de eisilado, publicado en 1952 en Buenos Aires.

De la relación personal entre Seoane y Piñeiro sabemos entre otras fuentes por la correspondencia conservada de Luís Seoane ${ }^{7}$, a

Se conservan un total de 70 cartas en cuyo remitente o destinatario figura Ramón Piñeiro. Todas las cartas referidas a continuación han sido tomadas del Epistolario de Luís Seoane publicado por el Consello da Cultura Galega (http://consellodacultura.gal/epistolarios/seoane.php). 
través de la cual no queda duda de que Seoane conocía los estudios en torno a la saudade que Piñeiro estaba llevando a cabo ${ }^{8}$.

En estas cartas se puede rastrear también el interés que Piñeiro mostraba en que Seoane conociera sus teorías filosóficas, así como podemos hacernos eco de la recepción que Fardel de eisilado tuvo en el líder del círculo de Galaxia: "Atopo nil unha gran forza emotiva, que sin dúbida é a que lle dá ise alento poético que envolve todo o libro. (...) Pódesme crer, querido Seone, que o teu Fardel de eisilado é un dos libros máis orixinais e sinceros que se escribiron na nosa língoa n-istes derradeiros anos".

Piñeiro escribirá además una pequeña reseña sobre el poemario que publicará en la revista $L a r^{10}$. En ese pequeño artículo destaca del poemario de su amigo la novedad que este supone en las letras gallegas, ya que lo considera el primer testimonio literario de la "manifestación das propias vivencias e problemas da experiencia migratoria" (Piñeiro 2007: 65), y el papel didáctico que podrá desempeñar su lectura en la sociedad gallega, quien podrá a través del poemario "aprender que a dor da emigración é algo máis fondo, máis duradeiro, máis trascendente que o emotivo esbagullarse da despedida" (Ibid.).

Deliberadamente omite Piñeiro la lectura política, de denuncia, de Fardel de eisilado y destaca tan sólo aquellos elementos que a él personalmente le interesan y que pueden servir para reforzar, aunque sutilmente, las tesis expuestas por él mismo en "Para unha teoría da saudade", y, que, como veremos, chocaban frontalmente con la concepción del sentimiento por parte de Seoane. En dicha reseña abundan palabras como "dor", "doenza", "transcendente" o "espiritualizada", léxico que poco tiene que ver con el empleado por el autor de Fardel de eisilado en su obra.

Podemos, por lo tanto, siguiendo a Arturo Casas (2010) especialmente, pero también a Méndez Ferrín (2011) ${ }^{11}$, resumir las diferencias políticas y artísticas entre Seoane y Piñeiro en el siguiente cuadro:

\begin{tabular}{|l|l|}
\hline Luís Seoane & Ramón Piñeiro \\
\hline Nacionalismo de exterior (América, exilio) & Nacionalismo de interior (Galicia, dictadura) \\
\hline Marxismo, materialismo histórico & Fenomenología existencial, esencialismo \\
\hline Sartre & Heidegger \\
\hline Historia (colectiva), memoria histórica ${ }^{12}$ & $\begin{array}{l}\text { Antropología, filosofía, psicología, hermenéutica y } \\
\text { metafísica }\end{array}$ \\
\hline Interculturalidad con América & Unidireccionalidad hacia Europa \\
\hline Apertura a la hibridación cultural & $\begin{array}{l}\text { Defensa de la ortodoxia identitaria, axialidad estática } \\
\text { de la lengua }\end{array}$ \\
\hline $\begin{array}{l}\text { Arte y literatura populares como soporte de la } \\
\text { memoria }\end{array}$ & Prácticas artísticas de marca formalista \\
\hline Utopía de una cultura pública y compartida & $\begin{array}{l}\text { Consciencia de la heteronomía y de la dependencia } \\
\text { cultural de la cultura gallega }\end{array}$ \\
\hline
\end{tabular}

8 Cf. carta de Piñeiro a Seoane fechada a 22/09/1951 y carta de Seoane a Piñeiro fechada a 19/01/1952

9 Cf. carta de Piñeiro a Seoane fechada a 17/03/1953.

10 Cf. carta de Piñeiro a Seoane fechada a 27/07/1953.

11 Xosé Luís Méndez Ferrín (1938-) como intelectual perteneciente a esa nueva generación de jóvenes, de una fuerte conciencia política, socialista e incluso independentista que en los años 60 se rebeló contra la tutela ideológica de Piñeiro (Miguélez Carballeira 2014: 222), no supo muy bien dónde encajar la posición ideológica y política de Seoane con respecto al piñeirismo.

12 Seoane era un "devoto fervente do que hoxe chamamos memoria histórica" (Méndez Ferrín 2011: 343). 
Así, a partir del análisis de este cuadro comparativo, podemos deducir un acuerdo, una coincidencia entre Piñeiro y Seoane al respecto de la importancia dada a la cultura gallega como factor dignificador de Galicia, pero un desacuerdo en la forma, en los repertorios culturales y políticos que se debían activar para lograr este fin.

Desde esta perspectiva intentaremos analizar cómo se manifiesta esta polémica en el poemario de Luís Seoane Fardel de eisilado, publicado en Buenos Aires en 1952, cómo en él se puede rastrear la postura tomada por el artista ante el piñeirismo y cómo el tema de la saudade es desarrollado en su poesía.

Ya la "Adicatoria e crida" del poemario supone una verdadera declaración de intenciones por parte de Luís Seoane de los fines que persigue con la escritura y publicación de su libro: la dignificación del pueblo gallego y la reescritura de su historia desde la colectividad a través de la narración de la odisea de su emigración: "o verdadeiro héroe de Galicia foi sempre o povo galego (...) E os homes xurdidos dese povo, Xohan Tourum, María Castaña (...) son en derradeiro termo os héroes, e non os famosos Condes do século XV como, ó xeito romántico, tratou de facernos creer unha historia de abondo aristocratizante" (Seoane 2002: 12).

Al destacar el carácter colectivo de la historia gallega y, además, al indicarnos como "o seu pulo primeiro xurdiu sempre da necesidade económica" (Ibid.), el pintor y escritor no esconde la motivación política, de corte marxista, que mueve la escritura de su poemario: "desexando continuar sendo, como fun deica agora pintando e escribindo un peón máis, aínda que isolado no traballo, na laboura coleitiva polo rexurdimento da cultura galega" (Ibid. 13), que, como decíamos, coincide con la labor cultural de Piñeiro.

Nombraba Seoane en el fragmento anteriormente señalado (Ibid. 12) a los héroes surgidos del pueblo como Xohan Tourum o María Castaña, por lo que ya podemos establecer una primera aparente similitud entre Mensagem y Fardel de eisilado al respecto de la representación del pueblo, del alma nacional a través de las figuras individuales. Analizábamos anteriormente los "héroes-mito" de Pessoa y de nuevo en el poemario de Seoane nos encontramos con nombres individuales que sirven como representación de una colectividad mayor.
Sin embargo, el planteamiento de ambos autores difiere en gran medida. En primer lugar los nombres escogidos por Pessoa para titular sus poemas son los nombres de grandes personajes históricos de su país, y aunque la idea de representatividad de la colectividad está presente en ellos, especialmente en algunos como Bandarra, "entendendo-se que Bandarra é um nome colectivo, pelo qual se designa (...) todos quantos viram, por seu exemplo, á mesma Luz" (Pessoa 1986: 166), el "héroe-mito" pessoano se concibe como aquel que mejor representa su época, es decir, como el elegido, el primus inter pares.

Por el contrario, los nombres que aparecen en Fardel de eisilado, como Ramón Cernadas, son los nombres de "héroes" anónimos o populares que representan a la colectividad (Casas 2010: 17). A Seoane le interesa el nombre de aquellos individuos que han sido relegados por la historia, acallados por los vencedores; le interesa destacar los nombres de los olvidados, de los campesinos y marineros anónimos: "Unha historia de Galicia, honradamente feita, non pode contar no seu haber con héroes isolados (...) senón cos movimentos coleitivos realizados polo povo galego a traveso do tempo" (Seoane 2002: 11); esos hombres que no representan a un pueblo, sino que lo encarnan. Por ello Seoane no duda en señalar héroes individuales como "Xohan Tourum, María Castaña, Ruy Xordo, María Pita, Sinforino Lopez" (Ibid. 12), ya que estos héroes no son "os famosos Condes do século XV" (Ibid.) sino que provienen del pueblo, son parte de la masa oprimida; son la individualización de una lucha colectiva de la que ninguno de ellos puede proclamarse cabeza. Inaugura, Seoane, así una nueva forma de crítica: "Foi o iniciador en 1952 da poesía de intención política nacional e antifexista en Galicia" (Méndez Ferrín 2011: 348), precediendo en diez años al que sería considerado el gran poemario civil de la literatura gallega, Longa noite de pedra, de Celso Emilio Ferreiro (Montero 2002: 77).

Como indica Méndez Ferrín (2011), en la poesía de Seoane el héroe mitológico último, el centro de la leyenda, de la odisea de la emigración, es el pueblo, y no, como en Pessoa, los hombres-mito en los que este se manifiesta. Como el mismo Seoane nos indica, en su poesía pesa más la visión social-realista que la artística: "Un poema non pode ser soio un prisma de cores, un xeito de xuntar verbas 
fermosas e producir soídos; é o berro de un home, o esgazamento que producen no seu esprito os feitos do pasado troncados en eternidad, en mito" (Montero 2002: 72).

Pero sí hay una importante similitud entre ambos. Luís Seoane se configura, igual que Pessoa, como un hacedor de mitos, mito del cual el pueblo es el centro (Méndez Ferrín 2011: 348). Así, personajes como Ramón Cernadas representan a todos los que como él han emprendido el viaje de la emigración (o, en su caso, de la colonización), asimilación entre el individuo y el grupo que se refuerza por el uso alterno de los verbos en primera persona del singular (Ramón Cernadas) y del plural (el pueblo gallego): "¡Eiquí estou, estamos, desagarimándo-los povoadores galegos!" ("Ramón Cernadas", "II. Eu, Ramón Cernadas, anos despois. 1975”, v. 5). De este modo, lo que logra Seoane en Fardel de eisilado es, a través de la presentación de diferentes momentos históricos y destinos de la emigración gallega a lo largo de dos siglos (desde la de Ramón Cernadas en el siglo XVIII a la suya propia y sus contemporáneos en el siglo XX), promover "unha comprensión da emigración como constante histórica" (Casas 2010: 18), pese a que la masa, aún estando insinuada, no llega a manifestarse como sujeto político (Ibid.). Así, los paralelismos con Mensagem no cesan ya que en el poemario de Pessoa el hilo narrativo también se configura históricamente, aunque cubriendo un número mayor de siglos, ya que el poemario del portugués se remonta a la fundación mítica de Lisboa por Ulises.

Abordando ahora el desarrollo del tema de la saudade en el poemario, podemos intuir ya que al tratarse de una poesía sobre emigración y exilio, y conociendo el tratamiento mayoritario del tema en la tradición literaria gallega, será la forma de saudade de la tierra la que tenga una mayor presencia, prácticamente absoluta, en el poemario de Seoane, aunque en algunos poemas como "Dende o Highland Princess" esta saudade de la tierra (saudade todavía presentida que no vivida, ya que el emigrante todavía se está alejando de la costa natal) se convierte en saudade de la raza, forma de saudade que aparece al converger la saudade de la tierra con el mensaje político anteriormente analizado:

Ises mortos tecerán no seu corazón, coma nós, xenerosas espranzas pra tódolos homes, novos [pensamentos, o mesmo que aqueles que, condanados ao silenzo, aínda viven esquecidos nas túas témeras cárceres, agachados coma alimañas nas covas sobrosas

[dos montes

ou atobados, arredrados de si mesmos, polas [afastadas rúas.

(vv. 22-27)

Pero es esta una forma de saudade de la raza que difiere de la de Pondal o de la Teixeira de Pascoaes; es una forma mucho más sutil y poética. Es una saudade que tan sólo se proyecta hacia el futuro, apenas hacia el pasado: no hay un pasado glorioso que añorar. Los únicos episodios históricos a los que alude Seoane no son hechos célebres o hazañas heroicas (la colonización gallega del siglo XVIII, la construcción del puente de Brooklyn durante el siglo XIX y la emigración de miles de gallegos anónimos durante los siglos XIX y XX), no pertenecen a ningún dorado pasado perdido, real o metafórico, que haya que recuperar, sino a un pasado que hay que denunciar.

Así, en el poemario, no es el recuerdo de ningún pasado añorado el que despierta la esperanza de los emigrados, la esperanza en un futuro mejor, sino la consciencia (colectiva) del país que se deja atrás, la consciencia de la condición de emigrante de su pueblo:

Doorido, dende o combés deste barco, véxote [debruzada ao mar.

Mais un día voltarei, derrubado e a vez

En moitedume, [afirmado polo tempo,

Con tódolos que erráneos coma eu andan [esparexidos polo mundo.

("Dende o Highland Princess", vv. 41-44)

Otro motivo comúnmente vinculado a la saudade de la tierra, no sólo en la literatura, sino también en la cultura popular y en otras formas artísticas como la música, especialmente el folk, aparece también en el poemario de Seoane: el deseo de no morir sin volver a ver la tierra materna, sin despedirse de ella, deseo que puede ser analizado como una variante del deseo de descansar en el suelo materno, de fundirse con la tierra natal en el último sueño de la muerte:

Voltando, a facer veu realidade o garimoso soño de non morrer lonxe sen ollar novamente os montes, o mar, os boscos da Terra

("Volta do vello emigrante. Tapiz", vv. 1-3) 
Es curioso que frente al deseo del emigrante de reposar en la tierra materna expresado por otros poetas (como aparece en Rosalía de Castro o en Lorenzo Varela), en Seoane nos encontramos, por el contrario, con la resignación del desterrado que es consciente de que va a morir lejos de la tierra que lo vio nacer, por lo que se contenta con simplemente poder volver a verla antes de morir. Resignación que, obviamente, no está exenta de denuncia:

Camiño dunha vida distinta, dunha norte [desvariada

viñamos eiquí, vindo a vivir, vivindo de moitos [xeitos

e tamén en certa maneira, vindo a morrer nesta [chauzada

de moitas mortes iñoradas, ficando no camino [sen cadaleitos

mortos de súpeto sobor desta terra, sen cruz, sen [viático,

sen familiares e sen vecinos que fagan o pranto [para xacer

con terra e ceo por sártego, baixo iste ceo [enimático,

rodeiados por caranchos buxeusque se veñen [abastercer

da nosa carne apodrecida, aquecida, enxoitada [polos ventos

até que os ósos fican amárelos, brancos, roídos [como as caaveiras

dos cabalos e das vacas, envueltos en lama seca, [arañentos,

mesmo loirecidas polos anos, esquecidas de [Deus, alcóntranse as oseiras.

("Ramón Cernadas", "I. Eu, Ramón Cernada, povoador galego. 1780”, vv. 21-32)

Por tanto, podemos concluir que aunque la saudade está presente en su desarrollo poético en la obra de Seoane, esta apenas se presenta como una fuerza pasiva o contemplativa, sino que prevalece el tono crítico y de denuncia. Seoane quiere que su obra no sólo sea bella estéticamente, sino que enseñe, aleccione, intervenga activamente en la historia y en la concepción creada socialmente en torno a esta (Montero 2002: 87). La saudade ya no es el lamento lastimero del desterrado morriñento, sino una fuerza constructiva, que le recuerda al emigrante su origen y todo lo que, y por lo que, aún le queda por luchar. Es una saudade destapada de todo el contenido filósofico u ontológico que Piñeiro quiso darle, mucho más humana y cotidiana. Es la saudade del trabajador, del campesino, y no la del intelectual. La vivida y no la contemplada o teorizada. Ya no es una lamentación, sino un grito esperanzado, el grito de denuncia con el que Seoane contesta a la saudade contemplativa del piñeirismo:

Puede que todo ello [Fardel de eisilado] sea un fracaso, me siento incapaz de juzgarme, pero lo que quiero expresar en definitiva es que no se puede continuar hablando de saudade y de impulso misterioso hacia occidente cada vez que un jornalero o casero emigra para resolver su problema personal o también económico (...) Todo el sentimiento de saudade es mínimo, es más fuerte en ellos el sentido de la realidad... (Carta de Luís Seoane a Carlos Maside fechada a 27/12/1952; Montero 2002: 71)

\section{Conclusiones y estado de la cuestión}

El análisis de la obra poética de Pessoa y de Seoane expuesto en este trabajo nos ha permitido ver cómo saudade, literatura, nacionalismo e historia son conceptos muy vinculados entre sí en la Galicia y Portugal de la primera mitad del siglo XX en autores como los examinados y pese a las divergencias que presentan, tanto el tema como su desarrollo, en una u otra orilla del Miño.

Pero, especialmente, hemos podido poner de manifiesto cómo las corrientes nacionalistas de la época fueron contestadas poéticamente por los escritores contemporáneos a estas, mostrando la capacidad protestaria y contestataria del arte; en el caso de Pessoa, reivindicando un nacionalismo abierto al mundo, universal en su particularidad, y en el de Seoane, un social-realismo de alto contenido político y un nacionalismo que no se ciñera al territorio gallego sino que tuviera en cuenta la hibridación cultural que se estaba produciendo en América. Además, estos autores no coinciden únicamente en el hecho de oponerse ideológicamente a las concepciones nacionalistas que primaban en su época (saudosismo y piñeirismo), promoviendo una visión mucho menos ortodoxa del nacionalismo, sino también en las formas artísticas escogidas para llevar a cabo esta denuncia, jugando en ambos autores un importante papel la concepción mítica del pueblo.

Finalmente, y a modo de conclusión más general, cabría preguntarse qué actualidad tiene seguir hablando, ya sea sentimental, nacional o literariamente de cuestiones como la saudade o el saudosismo en el mundo globalizado y permanentemente conectado del siglo XXI. 
Lo cierto es que la explotación de la saudade como tema literario e identitario se ha seguido dando a lo largo de todo el siglo XX y comienzos del XXI. José Colmeiro, por ejemplo, expone una serie de obras artísticas, todas muy recientes, en las que el rastro de la saudade es patente, aunque, como él mismo nos refiere, adaptada a las situaciones socioculturales y ecónomicas actuales, a la nueva realidad gallega, donde la desterritorialización y la hibridación cultural juegan un importante papel $^{13}$ :

A emigración, o desarraigamento, a transculturación e a saudade morriñenta son temas atlánticos que impregnan a cultura galega, cunha enorme influencia sobre a súa literatura, música e artes visuais, e son unha gran parte da hibridade cultural galega. Como testemuñas desta realidade, nos nosos días atopamos novelas e contos como A man dos paiños (2000), de Manuel Rivas, ou Tres trebóns (2005), de Xurxo Souto; películas como Mamasunción (1984), Gallego (1987), Sempre Xonxa (1989) ou Hotel Tívoli (2008) (...) e moitos outros máis. (Colmeiro 2013: 136-137)

A través de figuras como las de Fernando Pessoa, Luís Seoane o Méndez Ferrín hemos visto cómo la crítica al sentimentalismo no se ha dado únicamente en las últimas décadas del siglo XX, sino que su presencia es una constante a lo largo del siglo y cómo el proceso de revisión histórica y nacionalista, de desmitificación de términos como el de saudade, pese a todo lo que aún queda por decir, no es algo novedoso del nuevo milenio, sino que ya décadas antes nuestros intelectuales y artistas se pusieron frente a ellos y literariamente tomaron posición.

\section{Referencias bibliográficas}

Alonso Montero, Xesús (2002): As palabras do exilio. A Coruña: La Voz de Galicia.

Casas, Arturo (2010): "Individuo e grupo na obra poética de Luís Seoane”, Raigame: revista de arte, cultura e tradicións populares 33 , pp. 17-21.

Colmeiro, José F. (2013): "Visións periféricas, posicións globais: resituando a cultura galega contemporánea", Grial: revista galega de cultura 198, pp. 131-143.

Ferraz de Paula, Marcelo (2009): "Ressonâncias do passado na poesia de Álvaro de Campos e Augusto Casimiro", Todas as Letras. Revista de Língua e Literatura 10/2, pp. 55-61.

Lourenço, Eduardo (1996): "Sueño de imperio e imperio de sueño", Mensaje (Mensagem). Madrid: Hiperión, pp. 9-22.

(1999): Portugal como Destino seguido de Mitologia da Saudade. Lisboa: Gravida.

Lupi, João (1987): "Fernando Pessoa e a Filosofia Da Saudade", Revista portuguesa de filosofia 43.3/4, pp. 463-467.

Méndez Ferrín, Xosé Luís (2011): "Seoane no Fondo dos Espellos. Notas para un libro de memorias que se cadra non escribo", en R. Villares (ed.), Emigrante dun país soñado: Luís Seoane entre Galicia e Arxentina. Actas do Congreso Internacional Luís Seoane "Galicia-Arxentina, unha dobre cidadanía". Santiago de Compostela: Consello da Cultura Galega, pp. 339-351.

Miguélez-Carballeira, Helena (2014): Galiza, um povo sentimental? Género, politica e cultura no imaginário nacional galego. Santiago de Compostela: Através Editora.

Pascoaes, Teixeira de (1988): A saudade e o saudosismo: dispersos e opúsculos. Lisboa: Assirio \& Alvim.

Pérez López, Pablo Javier (2011): "Historia y Destino: el fatalismo como identidad nacional lusa", Diacronie. Studi di Storia Contemporanea 8/4, pp. 1-28.

Pessoa, Fernando (1986): Portugal, sebastianismo e Quinto Império. Publicações Europa-América.

13 Otros ejemplos de actualización del tema de la saudade los podemos encontrar en la obra de José Ángel Valente Cantigas de alén, en nuevos poetas como Elvira Riveiro (cf. su poema "Ekaterimburgo") e incluso en el cine en cintas como A cicatriz branca. La utilización y explotación de la saudade y el sentimentalismo también puede ser analizado en otros campos no literarios como la publicidad (cf. los recientes anuncios de la cadena de supermercados Gadis o de la marca Galicia), en donde es común la utilización comercial de la imagen sentimental de la tierra y el pueblo gallegos (Miguélez-Carballeira 2014: 255-259). Por su parte, la nueva crítica también se ha lanzado al estudio teórico del tema (cf. Miguélez-Carballeira 2014). 
(1990): Poemas de Álvaro de Campos. Lisboa: Imprensa Nacional, Casa da Moeda.

(1996): Mensaje (Mensagem). Madrid: Hiperión.

(2008) "Meu pensamento é um rio subterráneo", Arquivo Pessoa (http://arquivopessoa.net/ textos/2928).

Piñeiro, Ramón (2001): Filosofía da saudade. A Coruña: La Voz de Galicia.

(2007): “Un poema da emigración”, en Ramón Piñeiro. Olladas no futuro. Vigo: Galaxia, pp. 63-65.

Sadlier, Darlene Joy (1998): An Introduction to Fernando Pessoa: Modernism and the Paradoxes of Authorship. Gainesville: University Press of Florida.

Seoane, Luís (2002): Fardel de eisilado. A Coruña: La Voz de Galicia.

(2016): "Epistolario", en Epistolarios. Santiago de Compostela: Consello da Cultura Galega (http:// consellodacultura.gal/epistolarios/seoane.php).

Uribe, Jorge y Pedro Sepúlveda (2012): "Sebastianismo e Quinto Império: o nacionalismo pessoano à luz de um novo corpus", Pessoa Plural 1, pp. 139-162.

Souza, Raquel dos Santos Madanêlo (2007): "Augusto Casimiro e Fernando Pessoa: "nau... Portugal" e a conquista da "Distância",, Revista Crioula 1 (mayo) (http://www.revistas.usp.br/crioula/article/ view/52729). 